\title{
SUPERAÇÃO DE DORMÊNCIAE METODOLOGIAS PARA TESTES DE GERMINAÇÃO EM SEMENTES DE Trifolium riograndense Burkart E Desmanthus depressus Humb. ${ }^{1}$
}

\author{
ANADIAS SUÑÉ² LUCIABRANDÃOFRANKE $^{3}$
}

\begin{abstract}
RESUMO - O objetivo deste trabalho foi estudar métodos para superação da dormência e condução do teste de germinação em sementes de Trifolium riograndense Burkart e Desmanthus depressus Humb., leguminosas nativas ainda não relacionadas nas Regras para Análise de Sementes vigentes. $\mathrm{O}$ experimento foi dividido em duas etapas: na primeira, objetivando a superação da dormência, foram testados os tratamentos imersão em água aquecida a $60^{\circ} \mathrm{C}$, por cinco minutos; escarificação química com ácido sulfúrico concentrado por cinco minutos e escarificação manual com lixa $n^{\circ} 180$. Para a determinação das condições para o teste de germinação, avaliou-se os parâmetros luz (presença e ausência), substratos (papel e areia), posição da semente no substrato (sobre e entre) e diferentes temperaturas constantes $\left(5,10,15,20,25\right.$ e $\left.30^{\circ} \mathrm{C}\right)$. O delineamento experimental utilizado foi o completamente casualizado, com quatro repetições de 25 sementes cada. A imersão em água aquecida e a escarificação manual do tegumento com lixa são os tratamentos mais eficientes para a superação da dormência em sementes de $D$. depressus e $T$. riograndense, respectivamente. As sementes de $D$. depressus apresentam maior germinação na presença de luz, sobre substrato papel, a $25^{\circ} \mathrm{C}$, e as sementes de $T$. riograndense na ausência de luz, sobre substrato papel, a $30^{\circ} \mathrm{C}$. A temperatura alternada de $20-30^{\circ} \mathrm{C}$ é considerada adequada para a condução do teste de germinação, para ambas as espécies.
\end{abstract}

Termos para indexação: imersão em água quente, ácido sulfúrico, lixa, luz, temperatura, substrato.

OVERCOMING SEED DORMANCY AND METHODOLOGY FOR THE GERMINATION TESTS IN Trifolium riograndense Burkart AND Desmanthus depressus Humb. SEEDS

\begin{abstract}
The objective of this study was to investigate methods for overcoming seed dormancy and the germination test in Trifolium riograndense Burkart and Desmanthus depressus Humb, seeds, native legumes not yet included in the current Seed Analysis Rules. The experiment consisted of two parts: the first one was designed to overcome seed dormancy and the treatments were: immersion in hot water $\left(60^{\circ} \mathrm{C}, 5 \mathrm{~min}\right)$; chemical scarification with concentrated sulphuric acid for 5 minutes and manual scarification with number 180 sandpaper. For determination of the optimal conditions for the seed germination test, the variables evaluated were: the effects of light (presence and absence), substrate (paper and sand), seed position on the substrate (over and inside) and different constant temperatures $\left(5,10,15,20,25\right.$ and $\left.30^{\circ} \mathrm{C}\right)$. A completely randomized design with four replications ( 25 seeds each) was employed. The immersion in hot water and manual scarification with sandpaper were the more effective methods in breaking seed dormancy, of $D$. depressus and $T$. riograndense, respectively. Germination of $D$. depressus seeds was higher with presence of light, on paper substrate and at $25^{\circ} \mathrm{C}$. T. riograndense seeds germinated better with light absence, on paper substrate and under $30^{\circ} \mathrm{C}$. Alternates temperatures of $20-30^{\circ} \mathrm{C}$ was adequate for the germination tests for both species.
\end{abstract}

Index terms: immersion in hot water, sulfuric acid, sandpaper, light, temperature, substrate.

\footnotetext{
${ }^{1}$ Submetido em 11/04/2006. Aceito para publicação em 18/08/2006;

${ }^{2}$ Bióloga, Doutoranda do Programa de Pós-Graduação em Zootecnia Faculdade de Agronomia, UFRGS, Porto Alegre-RS, anasune@terra.com.br;
}

\footnotetext{
${ }^{3}$ Eng. Agrônoma, Dra, Professora Adjunta do Departamento de Plantas Forrageiras e Agrometeorologia - UFRGS, Porto Alegre-RS, lbfranke@vortex.ufrgs.br.
} 


\section{INTRODUÇÃO}

As pastagens nativas do Rio Grande do Sul são compostas por grande diversidade de espécies, sendo em sua maioria representadas por gramíneas de ciclo estival e, em menor quantidade, por leguminosas (Fonseca, 2000). No entanto, em se tratando do melhoramento destes campos é interessante que as leguminosas ocupem um lugar de destaque, pois não só melhoram a qualidade nutritiva das pastagens como também incrementam o teor de nitrogênio do solo via fixação simbiótica (Ledezma, 2000).

As recomendações necessárias à avaliação da qualidade das sementes estão, em grande parte, limitadas às espécies de maior interesse agrícola e, em geral, encontram-se associadas a programas que visam a produção de sementes certificadas, relegando as espécies nativas a segundo plano. Dentro desse contexto, situam-se Trifolium riograndense Burkart e Desmanthus depressus Humb., leguminosas nativas de bom e médio potencial forrageiro, respectivamente. $T$. riograndense pertence ao gênero Trifolium, o qual caracterizase por apresentar as leguminosas nativas mais importantes da estação hibernal, tanto pela qualidade como pela quantidade de forragem produzida (Miotto, 2001). A espécie é considerada endêmica do sul do Brasil, perene, rasteira, com talos estoloníferos longos e radicantes, com até $30-50 \mathrm{~cm}$ de comprimento e $0,15 \mathrm{~cm}$ de diâmetro, ocorrendo freqüentemente na metade norte do Rio Grande do Sul, sendo também conhecida como trevo serrano (Burkart, 1987). D. depressus, pertencente à Tribo Mimoseae, apresenta subarbustos prostados ou pouco ascendentes, com $10,0-40,0 \mathrm{~cm}$ de altura e legumes com 1,5-5,0cm de comprimento (Miotto, 2001). Ambas as espécies não possuem metodologia de condução do teste de germinação e métodos capazes de superar a dormência de suas sementes. Para tanto, o estudo relacionado aos fatores endógenos, os quais controlam a dormência, e aos fatores exógenos, ligados ao processo de germinação, complementam-se e se fazem cruciais na busca por uma semente de melhor qualidade.

A dormência das sementes de leguminosas é uma característica hereditária, atribuída à camada de células em paliçada, cujas paredes celulares são espessas e recobertas externamente por uma camada cuticular cerosa. Em condições naturais essa impermeabilidade se reduz gradualmente, de modo que certa proporção de sementes germina a cada período. Entretanto, em laboratório, a ruptura do tegumento permite a imediata embebição e o início do processo germinativo (Fernandez et al., 2000). Sendo assim, a imersão em água quente por alguns minutos, a escarificação com lixa e a escarificação química com ácido sulfúrico têm sido utilizadas, de forma bem sucedida, para eliminar a dormência nos tegumentos das sementes destas espécies (Perez, 2004).

A germinação de sementes em solos úmidos é promovida principalmente pelos fatores ambientais luz e temperatura. Esta última, no entanto, ganha importância extra, pois afeta tanto a velocidade como a porcentagem final de germinação (Carvalho e Nakagawa, 2000).

$\mathrm{O}$ estudo de temperaturas específicas em diferentes espécies se faz relevante ao considerar-se que as sementes apresentam capacidade germinativa em limites distintos de temperatura. Além disso, embora muitas sementes germinem em ampla variação de temperatura, elas geralmente não germinam abaixo ou acima de certa faixa específica para a espécie (Bewley e Black, 1994). A temperatura ótima para a maioria das espécies encontra-se entre $20-30^{\circ} \mathrm{C}$, sendo que, tanto abaixo quanto acima desta temperatura pode ser detectada a redução na velocidade do processo bem como no total de germinação (Kraemer et al., 2000).

Em relação ao fator luz, observou-se que as sementes da maioria das espécies cultivadas germinam bem tanto na ausência, quanto na presença de luz, entretanto, a luz se faz necessária para a germinação de várias espécies (Menezes et al., 2004). As sementes podem ser classificadas em três grupos, com relação às condições de luz durante a germinação: fotoblásticas positivas (não germinam na ausência de luz), fotoblásticas negativas (germinação é inibida pela luz) e indiferentes ao estímulo luminoso (Carvalho e Nakagawa, 2000).

O substrato e a posição da semente no mesmo também exercem influência marcante no processo germinativo. Fatores como tamanho da semente, sensibilidade à luz, facilidade que o substrato oferece para a realização das contagens e cobertura das sementes com papel de germinação podem favorecer ou prejudicar a germinação das mesmas (Scalon et al., 1993). Verifica-se que a escolha do substrato é muito importante para a obtenção dos melhores resultados em um teste de germinação, em vista, principalmente, da grande variação que existe entre as espécies com relação ao substrato mais adequado (Perez, 1999).

Considerando-se a carência de pesquisas sobre plantas nativas, especialmente quanto à questão da qualidade de suas sementes, este trabalho teve como objetivos avaliar o efeito de diferentes tratamentos sobre a dormência em sementes de Trifolium riograndense e Desmanthus depressus e determinar as condições de temperatura, substrato, forma de colocação 
da semente no substrato e regime de luz, na condução do teste de germinação, para ambas as espécies.

\section{MATERIAL E MÉTODOS}

As sementes de $T$. riograndense e $D$. depressus utilizadas são originárias de parcelas experimentais da Estação Experimental Agronômica (EEA) da Universidade Federal do Rio Grande do Sul (UFRGS), município de Eldorado do Sul e Fazenda Dois Açudes, município de Aceguá, RS, respectivamente. Após a coleta manual, realizada entre os anos de 2002 e 2003, as mesmas foram submetidas aos processos de limpeza, secagem em estufa com ventilação forçada de ar e então acondicionadas em refrigerador a $10^{\circ} \mathrm{C}$, dentro de sacos de papel até o início dos testes.

Os ensaios foram conduzidos no Laboratório de Análise de Sementes do Departamento de Plantas Forrageiras e Agrometeorologia da Faculdade de Agronomia da UFRGS, Porto Alegre, RS, no período de março a setembro de 2003. $\mathrm{O}$ primeiro experimento visou determinar o método mais eficiente para a superação da dormência presente das sementes e o segundo, padronizar a temperatura, a condição de luminosidade, o substrato e a posição da semente no substrato a serem empregados no teste de germinação.

Para ambos os ensaios as sementes foram alocadas em caixas gerbox, dentro de germinadores tipo BOD, com quatro repetições de 25 sementes por tratamento. A dificuldade de obtenção de sementes viáveis, em se tratando de espécies nativas, impossibilitou a utilização de número maior de sementes por repetição. Quando necessário, os substratos foram umedecidos com água destilada. Foram efetuadas contagens diárias a partir da primeira semente germinada, sendo considerada como tal aquela que evidenciava raiz primária com, no mínimo, 2 a $3 \mathrm{~mm}$ de comprimento (Gimenez-Sampaio et al., 1997). O período de duração dos testes foi de 21dias.

Para o primeiro experimento, as sementes foram submetidas às condições sobre papel, presença de luz, à temperatura de $20^{\circ} \mathrm{C}$ para $T$. riograndense, a qual é indicada para a maioria das espécies deste gênero nas Regras para Análise de Sementes (Brasil, 1992) e $30^{\circ} \mathrm{C}$ para D. depressus, temperatura obtida através de testes preliminares. Nesta etapa foram testados os seguintes tratamentos: (1) imersão das sementes em ácido sulfúrico (H2SO4) concentrado por 5 minutos, seguido de lavagem em água corrente, por 10 minutos; (2) imersão das sementes em água à temperatura de $60^{\circ} \mathrm{C}$ durante 5 minutos; (3) escarificação manual, com lixa número 180 e (4) sementes intactas (testemunha). O delineamento experimental utilizado foi o completamente casualizado e os dados em porcentagem, obtidos no teste de germinação, foram transformados em arco seno $\sqrt{\mathrm{X} / 100}$, para a normalização da sua distribuição. Quando houve significância no teste $\mathrm{F}$, as médias foram comparadas pelo teste de Tukey, a 5\% de probabilidade.

Após ter sido estabelecido o método mais eficaz para a superação da dormência em $T$. riograndense e $D$. depressus, as sementes foram submetidas a um segundo ensaio de germinação, em temperatura alternada de $20-30^{\circ} \mathrm{C}$, onde primeiramente avaliou-se a germinação em diferentes substratos, posição das sementes no substrato e condições de luminosidade. Desta forma foram testados os seguintes tratamentos: (1) sobre papel, com luz; (2) sobre papel, sem luz; (3) entre papel, com luz; (4) entre papel, sem luz; (5) sobre areia, com luz; (6) sobre areia, sem luz; (7) entre areia, com luz e (8) entre areia, sem luz. Para tanto, os tratamentos seguiram um sistema fatorial $2^{3}$ : presença e ausência de luz; substrato areia (previamente esterilizada a $200^{\circ} \mathrm{C}$ por 24 horas e peneirada) e papel (germitest) e sementes colocadas sobre e entre substrato. Na condição sem luz, as caixas gerbox foram cobertas com papel laminado, enquanto que na presença de luz foi usado fotoperíodo de 8 horas, utilizando-se quatro lâmpadas fluorescentes luz do dia.

O delineamento experimental utilizado foi $\mathrm{o}$ completamente casualizado e os dados em porcentagem, obtidos no teste de germinação, foram transformados em arco seno $\sqrt{\mathrm{X} / 100}$, para a normalização da sua distribuição. Quando houve significância no teste $\mathrm{F}$, as médias foram comparadas pelo teste de Tukey, a 5\% de probabilidade.

A partir dos resultados obtidos na primeira etapa deste ensaio, para ambas as espécies, foram testadas diferentes temperaturas constantes de germinação, consistindo nos seguintes tratamentos: (1) $10^{\circ} \mathrm{C}$, (2) $15^{\circ} \mathrm{C}$, (3) $20^{\circ} \mathrm{C}$, (4) $25^{\circ} \mathrm{C}$ e (5) $30^{\circ} \mathrm{C}$.

$\mathrm{O}$ efeito das diferentes temperaturas sobre a porcentagem de germinação das sementes foi submetido à análise de variância, considerando-se as diferenças estatísticas a 5\% de probabilidade. Aplicou-se a análise de regressão para avaliar a germinação das sementes com relação à temperatura constante. Além disso, utilizou-se o teste bilateral de Dunnett para fazer a comparação dos resultados obtidos na primeira etapa (temperatura alternada), com as temperaturas constantes da segunda etapa. 


\section{RESULTADOS E DISCUSSÃO}

A Tabela 1 apresenta as porcentagens médias de sementes germinadas, de sementes dormentes remanescentes e de sementes mortas e plântulas anormais para T. riograndense e D. depressus, submetidas a diferentes métodos de superação da dormência.

As sementes de $T$. riograndense e de $D$. depressus não submetidas a nenhum método de superação de dormência foram incapazes de ultrapassar $30 \%$ de germinabilidade total no final do teste de germinação (Tabela 1), ficando evidente a necessidade de tratamentos pré-germinativos capazes de reduzir a dormência em sementes com tegumentos duros.

A escarificação manual com lixa foi efetiva na promoção da germinação das sementes de $T$. riograndense, com valores de germinação significativamente superiores se comparado aos demais tratamentos testados neste ensaio. Estes resultados estão de acordo com os obtidos por vários autores, em condições de laboratório, mostrando a eficácia da escarificação através da utilização de materiais abrasivos na superação da impermeabilidade a água do tegumento de sementes de espécies de leguminosas forrageiras (Medeiros e Nabinger, 1996; Montardo et al., 2000; Leite e Soares, 2003). Aliado a isto, este tratamento proporcionou maior redução da porcentagem de sementes dormentes remanescentes (14\%) em relação à testemunha (63\%), o que torna este método, eficiente em superar a dureza, causada pela impermeabilidade do tegumento à água, em $T$. riograndense. Com relação à porcentagem de sementes mortas e plântulas anormais (4\%) não foram detectadas diferenças entre os métodos testados e entre estes e a testemunha, como pode ser observado na Tabela 1. Embora o uso da lixa provoque o rompimento dos envoltórios aumentando a permeabilidade da semente (Perez, 2004), o mesmo não se mostrou eficiente na superação da dormência na espécie $D$. depressus. Mesmo diferindo da testemunha, a escarificação manual aumentou a porcentagem final de germinação em apenas $30 \%$, em relação aos $54 \%$ de aumento propiciado pelo mesmo tratamento em $T$. riograndense. Além disso, com o uso da lixa, a porcentagem de sementes dormentes em $D$. depressus permaneceu alta (35\%), concordando com resultados obtidos por Garcia e Bassegio (1999), onde para sementes de outra leguminosa nativa, Desmodium incanum, foram verificadas $41 \%$ de sementes dormentes após este pré-tratamento.

Dentre os trabalhos realizados para superar a dormência em leguminosas, a imersão em água aquecida por certo tempo tem sido utilizada com sucesso para superar a dormência de tegumentos (Rosito et al., 1981; Moreira et al., 2003). A imersão das sementes de $D$. depressus em água a $60^{\circ} \mathrm{C}$, por cinco minutos, proporcionou as maiores porcentagens de germinação e a menor ocorrência de dormência (10\%). Resposta inversa foi possível de ser observada em sementes de $T$. riograndense (Tabela 1), uma vez que o mesmo tratamento apresentou elevação na porcentagem de germinação de apenas $19 \%$ em relação à testemunha e alta porcentagem de sementes dormentes remanescentes (41\%). Entretanto, o uso da água aquecida depende do tempo e da temperatura de embebição, em função da espécie a ser tratada o que, em alguns casos, faz com que este método não seja efetivo na superação da dormência em algumas sementes (Perez, 2004).

A escarificação química, para ambas as espécies estudadas, apresentou diferenças entre as sementes tratadas e a testemunha (Tabela 1). Todavia este tratamento não foi eficaz na superação da dormência, pois o porcentual de sementes dormentes remanescentes apresentou-se alto, tanto para $T$. riograndense como para $D$. depressus. Ainda, de acordo com a Tabela 1, pode-se observar que as sementes escarificadas quimicamente apresentaram considerável porcentagem de sementes mortas e plântulas anormais. Tais resultados indicam a necessidade de estudos mais detalhados quanto à concentração e tempo de embebição das sementes no ácido, pois mesmo sendo um método comprovadamente

TABELA 1. Médias (\%), das sementes germinadas (SG), dormentes (SD), mortas e plântulas anormais (SM + PA) de Trifolium riograndense e Desmanthus depressus submetidas a diferentes tratamentos para superação da dormência. UFRGS, 2003.

\begin{tabular}{lcccccr}
\hline \multirow{2}{*}{ Tratamentos } & T. riograndense & D. depressus & T. riograndense & D. depressus & T. riograndense & D. depressus \\
\cline { 2 - 7 } & \multicolumn{2}{c}{ SG } & \multicolumn{2}{c}{ SD } & SM + PA \\
\hline $\mathrm{H}_{2} \mathrm{O} / 5 \min$. & $47 \mathrm{~b}$ & $87 \mathrm{a}$ & $41 \mathrm{ab}$ & $10 \mathrm{a}$ & $12 \mathrm{a}$ & $3 \mathrm{a}$ \\
$\mathrm{H}_{2} \mathrm{SO}_{4} / 5 \mathrm{~min}$. & $53 \mathrm{~b}$ & $54 \mathrm{bc}$ & $38 \mathrm{ab}$ & $33 \mathrm{~b}$ & $9 \mathrm{a}$ & $13 \mathrm{a}$ \\
$\mathrm{Lixa}^{\circ} \mathrm{n}^{\circ} 180$ & $82 \mathrm{a}$ & $59 \mathrm{~b}$ & $14 \mathrm{~b}$ & $35 \mathrm{~b}$ & $4 \mathrm{a}$ & $6 \mathrm{a}$ \\
Testemunha & $28 \mathrm{c}$ & $29 \mathrm{c}$ & $63 \mathrm{a}$ & $67 \mathrm{c}$ & $9 \mathrm{a}$ & $4 \mathrm{a}$ \\
\hline
\end{tabular}

Médias seguidas pela mesma letra, na coluna, não diferem pelo teste de Tukey, a 5\% de probabilidade. 
eficiente para diversas espécies de leguminosas (Fernandez et al., 2000; Teles et al., 2000), a utilização de concentrações e períodos de embebição inadequados é capaz de propiciar a degradação do tegumento e a ruptura de células essenciais, favorecendo com isso a ocorrência de injúrias mecânicas e a invasão de fungos, prejudicando a porcentagem final de germinação das sementes (Zaidan e Barbedo, 2004).

Com relação à metodologia para a condução do teste de germinação, os resultados que determinaram a melhor condição de substrato, posição da semente no substrato e luminosidade encontram-se nas Tabelas 2 e 3, para $D$. depressus e $T$. riograndense, respectivamente.

As sementes de $D$. depressus, segundo a análise de variância, mostraram efeito significativo, a $5 \%$ de probabilidade, na interação entre o tipo de substrato e a forma de colocação da semente e entre o tipo de substrato e a condição de luminosidade. De acordo com a Tabela 2, nas sementes

TABELA 2. Médias (\%), de germinação das sementes de Desmanthus depressus submetidas a diferentes condições, sob temperatura alternada de $20-30^{\circ} \mathrm{C}$, UFRGS, 2003.

\begin{tabular}{lllll}
\hline Substrato & Forma & Com luz & Sem luz & Médias \\
\hline Papel & Sobre & 85 & 50 & $68 \mathrm{~A}$ \\
& Entre & 50 & 39 & $45 \mathrm{~B}$ \\
\hline Médias & & $68 \mathrm{a}$ & $45 \mathrm{~b}$ & 56 \\
\hline Areia & Sobre & 41 & 37 & $39 \mathrm{~B}$ \\
& Entre & 41 & 33 & $37 \mathrm{~B}$ \\
\hline Médias & & $41 \mathrm{~b}$ & $35 \mathrm{~b}$ & 38 \\
\hline Média geral & & 54 & 40 & \\
\hline
\end{tabular}

As médias seguidas de letras minúsculas distintas na linha, e maiúsculas na coluna, diferem significativamente, a $5 \%$ de probabilidade, pelo teste de Tukey.

TABELA 3. Médias (\%), de germinação das sementes de Trifolium riograndense submetidas a diferentes condições, sob temperatura alternada de $20-30^{\circ} \mathrm{C}$. UFRGS, 2003.

\begin{tabular}{lllll}
\hline Substrato & Forma & Com luz & Sem luz & Médias \\
\hline Papel & Sobre & $41 \mathrm{bc}$ & $79 \mathrm{a}$ & 60 \\
& Entre & $62 \mathrm{ab}$ & $56 \mathrm{bc}$ & 59 \\
\hline Média & & 51 & 67 & 59 \\
\hline Areia & Sobre & $34 \mathrm{c}$ & $43 \mathrm{bc}$ & 38 \\
& Entre & $34 \mathrm{c}$ & $40 \mathrm{bc}$ & 37 \\
\hline Média & & 34 & 42 & 38 \\
\hline Média geral & & 42 & 55 & 48 \\
\hline
\end{tabular}

Médias seguidas pela mesma letra não diferem pelo teste de Tukey, a 5\% de probabilidade. colocadas sobre substrato papel observou-se que a porcentagem de germinação foi significativamente superior àquela obtida em substrato areia, sem luz. Dentre todas as condições testadas, o tratamento sobre papel e presença de luz apresentou $85 \%$ de germinação, sendo significativamente superior aos demais.

Em T. riograndense, a análise de variância demonstrou haver interação significativa entre os três fatores testados, não sendo observadas diferenças nos tratamentos sobre papel, sem luz e entre papel, com luz. Quando as sementes foram colocadas sobre o substrato papel e na ausência de luz a porcentagem de germinação foi $18 \%$ superior ao tratamento no qual as sementes foram colocadas entre papel e na presença de luz. Portanto, os melhores resultados entre os tratamentos testados foram obtidos na ausência de luz e sobre o substrato papel, com $79 \%$ de germinação, como pode ser observado na Tabela 3.

Segundo Machado et al. (2002), a utilização do substrato adequado é fundamental para a germinação das sementes, uma vez que pode levar à maior ou menor dificuldade de avaliação das plântulas, aos problemas relativos à secagem excessiva e à presença de fungos, o que de certa forma coloca a utilização da areia em desvantagem para as duas espécies estudadas neste experimento, uma vez que o mesmo não mostrou a mesma praticidade na avaliação das sementes germinadas se comparado ao substrato papel.

Enquanto a umidade, o oxigênio e a temperatura favorável são essenciais para a germinação de todas as sementes, as respostas das mesmas em relação à luz podem se mostrar variáveis. Estas diferenças podem ser verificadas nas Tabelas 2 e 3 , onde $D$. depressus e $T$. riograndense, apresentaram maior germinação na presença e ausência de luz, respectivamente. Entretanto, mesmo detectando-se diferenças significativas para a condição de luminosidade, nas duas espécies, não seria adequado classificá-las como fotoblásticas positivas ou negativas "absolutas" pois, tanto as sementes de $D$. depressus como as de $T$. riograndense germinaram na ausência e presença de luz, respectivamente. Estas condições fazem das sementes de $D$. depressus e de $T$. riograndense fotoblásticas positivas e negativas "preferenciais", respectivamente, segundo a classificação de Klein e Felippe (1991).

Em uma segunda fase do experimento, onde foram estudadas diferentes temperaturas constantes de germinação, a análise da variância mostrou diferenças significativas para os tratamentos testados. Para a germinação de sementes de D. depressus, pode-se estabelecer a temperatura ótima ao redor 
de $30^{\circ} \mathrm{C}$ (Figura 1a). Já para as sementes de $T$. riograndense, pode-se estabelecer a temperatura ótima de germinação ao redor de $25^{\circ} \mathrm{C}$, conforme pode ser observado na Figura $1 \mathrm{~b}$. A partir dos resultados obtidos foi possível, portanto, determinar a temperatura ótima teórica de incubação em 30 e $25^{\circ} \mathrm{C}$ para a maximização da porcentagem final de germinação das sementes de $D$. depressus e $T$. riograndense, respectivamente. Em ambas as espécies estudadas a faixa de germinação observada foi bastante ampla, entre 5 e $30^{\circ} \mathrm{C}$, uma vez que foi possível verificar a formação de plântulas normais entre estas temperaturas. Para $D$. depressus houve aumento na germinação das sementes até o ponto máximo de $30^{\circ} \mathrm{C}$ (Figura 1a). Resultados semelhantes foram descritos por Cavalcante e Perez (1995), em sementes de Leucaena leucocephala, onde a faixa de germinação situou-se basicamente entre 20 e $35^{\circ} \mathrm{C}$ e, dentro desta faixa, $30^{\circ} \mathrm{C}$ foi apontada como a temperatura ótima de germinação. Os mesmos autores sugerem uma tendência das sementes de leguminosas forrageiras tropicais
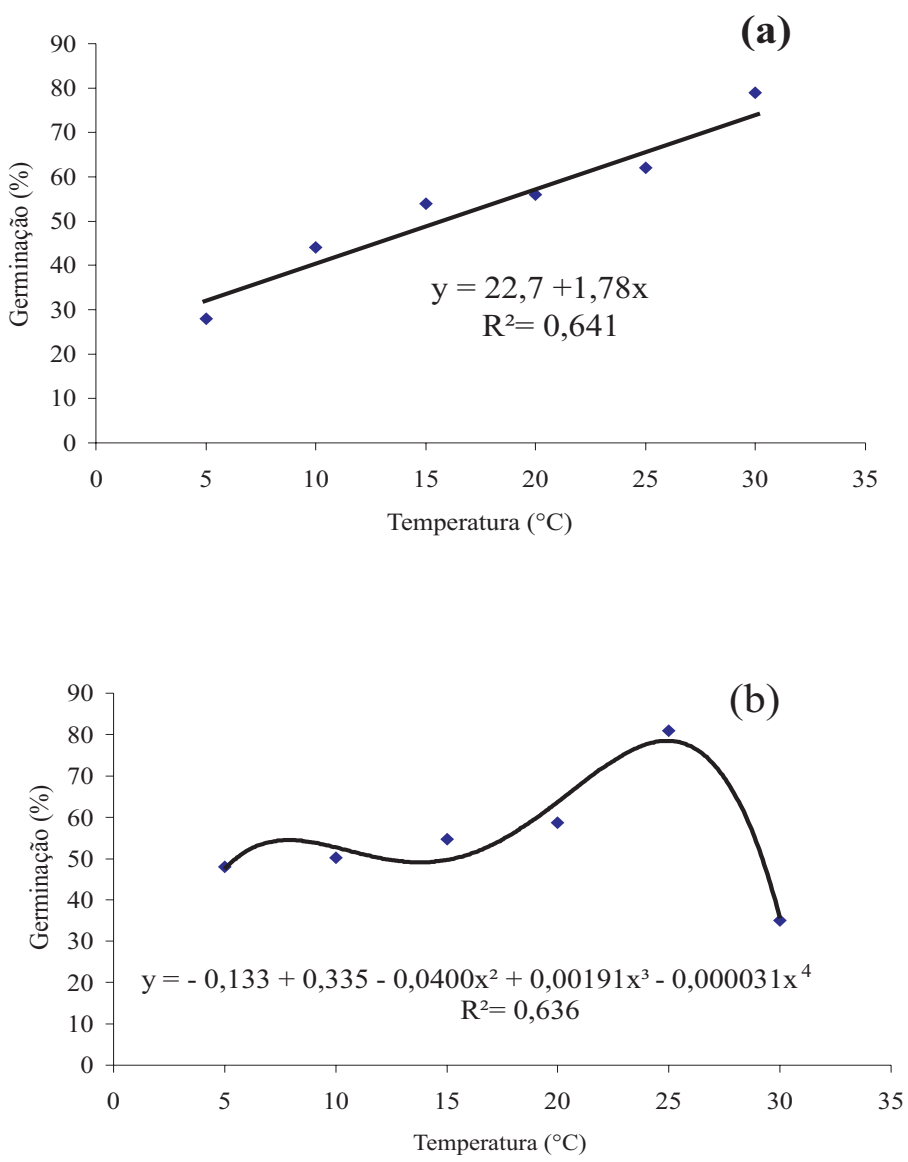

FIGURA 1. Relação entre a porcentagem de germinação e diferentes temperaturas constantes em sementes de $D$. depressus (a) e Trifolium riograndense (b). UFRGS, 2003. apresentaram maior germinaçao em condições de laboratório, em temperaturas em torno de $30^{\circ} \mathrm{C}$.

Entretanto, no caso de T. riograndense, temperaturas mais elevadas aumentaram a porcentagem de germinação, dentro de certo limite, uma vez que temperaturas acima de $25^{\circ} \mathrm{C}$ provocaram acentuada queda na porcentagem de germinação das sementes desta espécie (Figura 1b). Estes resultados corroboram com a afirmação, feita por Neto et al. (2002), de que dentre os agentes externos capazes de regular o processo germinativo, o uso de temperaturas elevadas é reconhecido como fator potencialmente deletério, capaz de ocasionar estresse no processo germinativo para as sementes de muitas espécies, incluindo a $T$. riograndense.

Segundo Carvalho e Nakagawa (2000), é essencial ressaltar que os efeitos da temperatura sobre a germinação são complexos, pois podem afetar cada estágio do processo germinativo de diferentes maneiras, além de estarem relacionados aos processos bioquímicos aos quais as sementes são sujeitas. Sendo assim, o desenvolvimento de pesquisas abordando o mesmo tema, mas contemplando diferentes fatores capazes de influir no processo relacionado à temperatura de germinação das sementes seriam extremamente úteis na avaliação da qualidade das mesmas. Entretanto, de modo geral, a relação entre o comportamento de germinação e a temperatura está associada às temperaturas as quais normalmente as plantas ficam expostas durante a estação de crescimento (Bryant, 1989). Desta maneira, considerandose $D$. depressus e $T$. riograndense, como leguminosas de crescimento primavero-estival e hibernal (Boldrini et al., 1985; Souza, 1985) respectivamente, as temperaturas de 30 e $25^{\circ} \mathrm{C}$, adequam-se, de certo modo, ao padrão germinativo destas espécies.

Aplicou-se o teste bilateral de Dunnett para $D$. depressus e $T$. riograndense, respectivamente, comparando diferentes temperaturas constantes com a temperatura alternada de 20 $30^{\circ} \mathrm{C}$, utilizada na primeira fase do experimento. Em $D$. depressus, a análise dos dados revelou que a porcentagem de germinação sob temperaturas constantes diferiu significativamente da temperatura de $20-30^{\circ} \mathrm{C}$, exceção feita à temperatura de $30^{\circ} \mathrm{C}$. Resultados semelhantes foram observados em $T$. riograndense onde, excetuando a temperatura de $25^{\circ} \mathrm{C}$, as demais mostraram diferenças significativas em relação à temperatura alternada de $20-30^{\circ} \mathrm{C}$.

De acordo com as médias de germinação obtidas verificou-se que as temperaturas de 30 e $25^{\circ} \mathrm{C}$ seriam as mais indicadas em termos de temperaturas constantes, para $D$. depressus e T. riograndense, respectivamente. Entretanto, a 
utilização da temperatura alternada de $20-30^{\circ} \mathrm{C}$, no caso de D. depressus, aumentou em seis pontos porcentuais a média final de germinação em relação à temperatura de $30^{\circ} \mathrm{C}$, considerada ideal para espécie. Estes resultados estão em conformidade com as observações de Silva e Aguiar (2004), que, para muitas espécies, temperaturas alternadas podem mostrar-se benéficas ao processo de germinação. Tais dados podem ser melhor explicados ao considerar que o estímulo à germinação pode ser conseqüência de um efeito das variações de temperatura nas diversas fases da germinação, agindo sobre o processo de dormência ou simplesmente acelerando a germinação em sementes não dormentes (Copeland e McDonald, 1995).

Contudo, em trabalhos realizados por Franke e Bassegio (1998), com sementes de Desmodium incanum foi possível demonstrar que tais espécies não apresentam exigência de flutuação de temperaturas durante o desenvolvimento do processo germinativo, pois temperaturas constantes de $30^{\circ} \mathrm{C}$ foram superiores à temperatura alternada de $20-30^{\circ} \mathrm{C}$, para ambas as espécies. Estas diferenças nos resultados corroboram o fato da temperatura de germinação variar de acordo com as espécies estudadas.

\section{CONCLUSÕES}

A escarificação térmica, através da imersão em água a $60^{\circ} \mathrm{C}$ por cinco minutos e a escarificação manual do tegumento com lixa são tratamentos eficientes para a superação da dormência em sementes de $D$. depressus e $T$. riograndense, respectivamente.

As sementes de $D$. depressus apresentam maior germinação na presença de luz, sobre substrato papel, a $25^{\circ} \mathrm{C}$, e as sementes de $T$. riograndense na ausência de luz, sobre substrato papel, a $30^{\circ} \mathrm{C}$.

Para ambas as espécies, a temperatura alternada de 20$30^{\circ} \mathrm{C}$ é considerada adequada para a condução do teste de germinação.

\section{REFERÊNCIAS}

BEWLEY, J.D.; BLACK, M. Physiology and biochemistry of seeds in relation to germination: viability, dormancy and environmental control. Berlin: Spring-Verlag, Berlin, 1982. 375p.

BOLDRINI, I.I.; MIOTTO, S.T.S.; BOECHAT, S.C. Gramíneas e leguminosas. Porto Alegre: UFRGS, Instituto de Botânica, 1985. $140 \mathrm{p}$.

BRASIL. Ministério da Agricultura e Reforma Agrária. Regras para análise de sementes. Brasília: SNDA/DNDV/CLAV, 1992. 365 p.

BRYANT, J.A. Fisiologia da semente. São Paulo: EPU, 1989. 84p.

BURKART, A. Trifolium L. In: Flora Ilustrada de Entre Rios (Argentina) v.6, n.3, Buenos Aires: I.N.T.A., 1987, p.219-662.

CARVAlho, N.M.; NAKAGAWA, J. Sementes: ciência, tecnologia e produção. 3. ed. Campinas: Fundação Cagill, 2000. $424 p$.

CAVALCANTE, A.M.B.; PEREZ, S.C.J.G. Efeitos da temperatura sobre a germinação de sementes de Leucaena leucocephala (Lam.) de Wit. Revista Brasileira de Sementes, Brasília, v.17, n.1, p.1-8, 1995.

COPELAND, L.O.; McDONALD, M. Principles of seeds science and technology. New York: Chapman Hall, 1995. 409p.

FERNANDEZ, C.D.; GROF, B.; CARVALHO, J. Escarificação mecânica de sementes de Stylosanthes spp. com beneficiadora de arroz. In: Embrapa. Comunicado Técnico:, 2000.

FONSECA, E.L. Caracterização Espectral e índices de vegetação em Paspalum notatum Flügge var. notatum com vistas a modelagem de crescimento.:, 2000. 60f. Dissertação (Mestrado). Universidade Federal do Rio Grande do Sul, Porto Alegre, 2000.

FRANKE, L.B.; BASSEGIO, J. Superação da dormência de sementes de Desmodium incanum DC. e Lathyrus nervosus Lam. Revista Brasileira de Sementes, Brasília, v.20, n.2, p.420-424, 1998.

GARCIA, E.N.; BASSEGIO, J.B. Poder germinativo de sementes de Desmodium incanum DC. (Leguminoseae). Revista Brasileira de Agrociência, Brasília, v.5, n.3, p.199-202, 1999.

GIMENEZ SAMPAIO, T.; SAMPAIO, N.V.; VAZ DE SOUZA, R.H. Incremento na taxa e velocidade de germinação sob baixas temperaturas, de sementes de milho (Zea mays L.) submetidas ao pré-condicionamento osmótico. Revista Científica Rural, Bagé, v.2, n.1, p.20-27, 1997.

KLEIN, A.; FELIPE, G.M. Efeito da luz na germinação de sementes de ervas invasoras. Pesquisa Agropecuária Brasileira, Brasília, v.26, n.7, p.955-966, 1991.

KRAEMER, K.H.; KÂMPF, A.N.; ÁQUILA, M.E.A. Luz e temperatura na germinação de sementes de Tibouchina urvilleana. Revista Brasileira de Horticultura Ornamental, Campinas, v.26, n.1/2, p.39-45, 2000.

LEDEZMA, E.A.P. Produção de sementes de Macroptilium lathyroides (L.) Urb. em função do espaçamento e épocas de colheita. 2000. 70f. Dissertação (Mestrado) - Faculdade de Agronomia Eliseu Maciel, Universidade Federal de Pelotas, Pelotas, 2000.

LEITE, I.C.; SOARES, F.H. Avaliação de métodos de escarificação sobre a germinação de sementes de Macroptilium atropurpureum CV. SIRATRO. Informativo ABRATES, Londrina, v.13, n.3, p.456, 2003.

MACHADO, C.F.; OLIVEIRA, J.A.; DAVIDE, A.C.; GUIMARÃES, R.M. Metodologia para a condução do teste de germinação em sementes de ipê-amarelo. Cerne, Lavras, v.8, n.2, p.18-27, 2002.

MEDEIROS, R.B.; NABINGER, C. Superação da dormência em sementes de espécies forrageiras. Revista Brasileira de Sementes, Brasília, v.18, n.2, p.193-199, 1996. 
MENEZES, N.L.; FRANZIN, S.M.; ROVERSI, T.; NUNES, E.P. Germinação de sementes de Salvia splenden Sellow em diferentes temperaturas e qualidades de luz. Revista Brasileira de Sementes, Brasília, v.26, n.1, p.32-37, 2004.

MIOTTO, S.T.S. Leguminoseae-Faboideae. Porto Alegre: UFRGSI, Instituto de Botânica, 2001. 112p.

MONTARDO, D.P.; CRUZ, F.P.; CAETANO, J.H.; EGGERS, L.; BOLDRINI, I.I.; DALL' AGNOL, M. Efeito de dois tratamentos na superação de dormência de sementes de cinco espécies de Adesmia DC. Revista Científica Rural, Bagé, v.5, n.1, p.1-7, 2000.

MOREIRA, F.J.C.; SILVA, M.A.P.; MEDEIROS FILHO, S. Efeitos de tratamentos pré-germinativos em sementes de Apeiba tibourbou Aubl. Informativo ABRATES, Londrina, v.13, n.3, p.159, 2003.

NETO, J.C.A.; AGUIAR, I.B.; FERREIRA, V.M.; RODRIGUES, T.J.D. Temperaturas cardeais e efeito da luz na germinação de sementes de mutumba. Revista Brasileira de Engenharia Agrícola e Ambiental, Campina Grande, v.6, n.3, p.460-465, 2002.

PEREZ, S.C.J.G.A. Envoltórios. In: FERREIRA, A. G.; BORGHETTI, F. Germinação: do básico ao aplicado. Porto Alegre: Artmed, 2004. p.125-134.

PEREZ, S.C.J.G.A. Influência do armazenamento, substrato, envelhecimento precoce e profundidade de semeadura na germinação de canafístula. Bragantia, Campinas, v.58, n.1, p.5768,1999
ROSITO, J.M.; NABINGER, C.; MARASCHIN, G.E. Quebra de dormência de sementes de Trifolium vesiculosum Savi. cv. Yuchi. In: REUNIÃO DA SOCIEDADE BRASILEIRA DE ZOOTECNIA, 18., 1981, Goiânia. Resumos... Goiânia: SBZ, 1981. p.95.

SCALON, S.P.Q.; ALVARENGA, A.A.; DAVIDE, A.C. Influência do substrato, temperatura, umidade e armazenamento sobre a germinação de sementes de pau-pereira (Platycyamus regnelli Benth). Revista Brasileira de Sementes, Brasília, v.15, n.1, p.143146, 1993.

SILVA, M.M.L.; AGUIAR, I.B. Efeitos dos substratos e temperaturas na germinação de sementes de Cnidosculus phyllancathus Pax \& K. Hoffm. (Faveleira). Revista Brasileira de Sementes, Brasília, v.26, n.1, p.9-14, 2004.

SOUZA, E.H. Caracterização morfológica e fisiológica das formas diplóide e tetraplóide de Trifolium riograndense Burkart em comparação com Trifolium repens $\mathrm{L}$. e Trifolium polymorphum Poir. 1985. 125p. Dissertação (Mestrado). Universidade Federal do Rio Grande do Sul, Porto Alegre, 1985.

TELES, M.M.; ALVES, A.A.; OLIVEIRA, J.C.G.; BEZERRA,A.M.E. Métodos de quebra de dormência em sementes de Leucaena leucocephala (Lam) de Wit., Revista Brasileira de Zootecnia, Viçosa, v.29, n.2, p.387-391, 2000.

ZAIDAN, L.B.P.; BARBEDO, C.J. Quebra de dormência em sementes. In: FERREIRA, A.G.; BORGHETTI, F. Germinação: do básico ao aplicado. Porto Alegre: Artmed, 2004. p.136-146. 